\title{
Clinical analysis of vulvar cancer
}

\author{
Raghvendra Thakur ${ }^{1}$, Zheng Xuehua ${ }^{2}$, Zhang Mengli ${ }^{1}$, Wu Yanjun ${ }^{1}$, \\ Tian Yuan ${ }^{1}$, Zheng Guiying ${ }^{1}$
}

\begin{abstract}
${ }^{1}$ Department of Obstetrics and Gynecology, Second Hospital of Jilin University, Norman Bethune College of Medicine, Ziqiang Street, Changchun, P.R. China-130061

${ }^{2}$ Department of Obstetrics and Gynecology, Maternity and Children Hospital, Jilin Province, Liaoyuan City, Jilin Province, P.R. China-130037
\end{abstract}

Received: 9 May 2013

Accepted: 15 June 2013

\section{*Correspondence:}

Dr. Raghvendra Thakur

E-mail: thakurrags@hotmail.com

(C) 2013 Thakur $\mathrm{R}$ et al. This is an open-access article distributed under the terms of the Creative Commons Attribution Non-Commercial License, which permits unrestricted non-commercial use, distribution, and reproduction in any medium, provided the original work is properly cited.

\begin{abstract}
Background: The purpose of this study is to understand the incidence, related factors, and the prognosis factors in order to avoid risk, proper method of diagnosis and treatment and reduce complications and provide the basis.

Methods: 85 Vulvar cancer (VC) patients treated in our hospital from 2002.10 to 2012.10 were collected and analyzed by retrospective comparative methods. SPSS19.0 application software was used for the statistical analysis. The clinical data are analyzed by chi-square and $\mathrm{F}$ test statistic methods. $\mathrm{P}<0.05$ was a significant difference between the judgment standard.

Results: During 10 years, we treated 3391 cases of the primary malignant tumors including 85 VC cases; VC was $2.89 \%$ (85/3391). The age was between $24 \sim 88$ years old, mean was $57.09 \pm 12.93$ yrs. old, variable age of the VC had been juvenescence trend $(F=6.013, \quad P=0.016<0.05=)$. The differences between the urban and rural residential area have some influence to the onset of VC. Rural patients are more than urban patients. By statistical analysis, region distribution in these two groups was remarkably different=4.16, $P=0.045<0.05$, but the urban proportion of patients in different years has no difference $(\chi 2=0.080, P=0.777)$.

Conclusion: The number of cases increased progressively in young age. VC patients were more in rural area than urban. History of malignant tumor and obesity has the positive correlation with VC. High-risk groups should be alert to the possibility of VC. Preoperative diagnosis should be Colposcopic, biopsy in order to improve the accuracy of earlier diagnosis. Vulvar resects have an effect on the healing of the incision. Follow-up rate is low; It is difficult to say statistically survival rate is 5 years.
\end{abstract}

Keywords: Cancer, Vulvar, Recurrence, Chemotherapy, Gynecological, Malignant

\section{INTRODUCTION}

Vulvar cancer (VC) is about $3 \%$ to $5 \%$ of all primary gynecological malignancies, annual incidence rate is about 2 to $3 / 10 .^{1}$ The vast majority of vulvar lesion occurs in the genital skin surface with early symptoms like vulvar itching, pain, small excrescence. Early diagnosis rate of Vulvar cancer are increasing nowadays. Vulvar cells similar to a cervical cytology brush (Rovers Medical Devices BV) are expected to become an important tool in the prevention and early diagnosis of vulvar cancer. In addition, CT examination with high specificity in vulvar cancer lymph node metastasis, improve the accuracy of the preoperative diagnosis. The range of options such as surgery, selective sentinel node and inguinal lymph node dissection, therapeutic applications, Chemotherapy or a combination of chemotherapy treatment etc is available. VC originates from 2 different etiologies. A class of histological features of well differentiated keratinizing squamous cell 
carcinoma: occurs in women over the age of 50 and often concomitant vulva non-neoplastic epithelial lesions (VNED) such as chronic inflammation, genital lichen sclerosis. This types of lesions in the HPV-DNA detection rate is low $(<15 \%)$. Histological features mostly as epidermal carcinoma (Bowen's carcinoma, warty carcinoma), are common in young women. Epidemiological this type of VC risk factors includes smoking, sexually transmitted diseases (STD), and immune suppression. Most study shows that this type of lesions in the HPV-DNA, especially HPV16, \& 18 accounts for $40 \%$ to $51 \%$, often with concomitant cervical lesions. ${ }^{2}$ Lymph node metastasis has greater impact on the prognosis of VC. FIGO Committee Gynecologic Oncology Group revised the staging of vulvar cancer lymph node involvement. ${ }^{3}$ In the new staging, no lymph node metastasis \& invasion of adjacent organs cases regardless of the size of the lesion- divided into phase I. Only invasion of adjacent organs, but no lymph node metastasis were divided into Phase II; lymph node metastasis were divided into Phase III with subdivision of lymph node involvement. Surgery such as genital radical resection + inguinal lymph node resection for the vulvar traditional standard technique, this surgical inguinal lymph node dissection routinely cut off the great saphenous vein stripping fascia lata. This technique has large range of damage, and delayed healing, often appear as a lymphatic retention cyst, lower extremity edema, incontinence, sexual dysfunction, and seriously affecting the quality of life of patients. About $90 \%$ of vulvar squamous cell carcinoma, adenocarcinoma, squamous cell carcinoma of all anti-cancer drug sensitivity is lower; the chemo treatment of VC often can be used as a vulvar advanced cancer or recurrent VC. Chemotherapy drugs are mitomycin C (MMC), bleomycin (BLM), cisplatin (DDP), methotrexate (MIX), and cyclohexyl nitrosourea (CCNU). The implementation of concurrent radiotherapy and chemotherapy can achieve better efficacy. 5 Fluorouracil (5-FU) or 5-FU + cisplatin combination chemotherapy is the most commonly used chemotherapy regimens. Hamp ${ }^{4}$ identified HPV vaccine is feasible to reduce the reproductive tract disease. Since Merck Gardasil cervical cancer preventive vaccines listed, the vaccine in the prevention of its related vulvar and vaginal intraepithelial neoplasia. The vaccine is beneficial for all young women and even in existing HPV infection. In addition, the treatment of $\mathrm{VC}$ can also consider the use of laser-assisted and immunomodulatory drugs combined with chemotherapy treatment achieved satisfactory results. The treatment of $\mathrm{VC}$, surgeons and scholars considered the main problem is how to improve the survival rate, at the same time minimize postoperative complications, improve quality of life \& prevention of recurrence. The present study is more focused on the treatment options, but its advantages and feasibility still a large number of evidence-based medicine support. With the sentinel lymph node biopsy technique of continuous research and improvement and development of the genital reconstruction techniques, we have reason to believe it will find the best treatment of $\mathrm{VC}$, so that patients get the maximum therapeutic benefit with minimal trauma.

\section{METHODS}

$85 \mathrm{VC}$ patients treated in the obstetrics and gynecology at the second hospital of the Jilin University from October 2002 to October 2012 were collected and analyzed by retrospective comparative methods:

1) The incidence trend of $\mathrm{VC}$

2) analyze the invasion related factors of $\mathrm{VC}$

3) The diagnostic methods and the reliability of Vular.

4) The effect of Peroperative Period recuperative of VC patients by different modus operandi

5) To analysis infiltration and metastasis of $\mathrm{VC}$ by the type of pathological tissue of differentiation.

Record and the establishment of database. SPSS19.0 application software for the statistics. The clinical data are analyzed by chi-square and $\mathrm{F}$ test statistic methods. $\mathrm{P}$ $<0.05$ as a significant difference between the judgment standard.

\section{RESULTS}

During 10 years, we treated 3391 cases of the primary malignant tumors that occurred in the department of Gynecology in our hospital, including $85 \mathrm{VC}$ cases, the percentage of VC was $2.89 \%$ (85/3391). The age of 85 VC patients was between $24 \sim 88$ years old, mean age was $57.09 \pm 12.93$ years old, Compares the four periods of the patient's age distribution, found that the variable age of the $\mathrm{VC}$ had been juvenescence trend $(F=6.013$, $P=0.016<0.05$. The differences of the urban and rural residential area might have some influence to the onset of VC. Rural patients are more than urban patients. By statistical analysis, region distribution in these two groups was remarkably different $(F=4.16, P=0.045<0.05)$, but the urban proportion of patients in different years has no difference $(\chi 2=0.080, \quad P=0.777)$.

The proportion of VC patients with menopause was $58.82 \%(50 / 85)$, the proportion of postmenopause had been changed from the first two years of $87.5 \%(7 / 8)$ dropped to the last two years of $48.72 \%$ (19/39), but nomenopause's proportion had been raised, from $12.5 \%$ $(1 / 8)$ to $51.28 \%(20 / 39)$. By statistical analysis, this change has no significance. By statistical analysis, positive correlation, malignant tumor history and the history of genital surgery had some correlation with the onset of VC $(P<0.05)$.

The misdiagnose of 4 cases, accounting for $4.71 \%$ of the total, the tentative preoperative diagnosis is: Bartholin's abscess, Vulva black nevi and the benign tumor of the vulva. 
Compare the result of the preoperative biopsy with postoperative pathologic, pathological types of accuracy is better, for $93.58 \%$, organizational the accuracy of differentiation degree average, at $83.33 \%$.

The scope of the vulva surgery effected the patient's incision healing and hospital length of stay; while with the same vulvar resects scope, inguinal lymph node dissection had no effect to the postoperative incision recovery, but significantly increased the hospital day of those who underwent simple vulvectomy.

Pathological types: Squamous-cell type still accounts for significantly larger proportions in VC (84.71\%), the proportions of vulvar malignant melanoma is $5.88 \%$, Basal cell carcinoma is $4.71 \%$, Verrucous cell carcinoma is $3.53 \%$ and Paget's extramammary is $1.18 \%$.

Clinical stage: among $85 \mathrm{VC}$ patients 30 patients had FIGO stage I, 41 stage II, 13 stage III, and 1 stage IV disease.

The main clinical manifestations were vulvar pruritus $(70.59 \%)$ and neoplasm $(56.47 \%)$. Patients with lateral side lesions were 62 , and the linear side lesions were23 cases; 3 groups can be divided by the maximum diameter of the lesion: $<2 \mathrm{~cm}, 2 \mathrm{~cm} \sim 5 \mathrm{~cm}$ and $>5 \mathrm{~cm}$, and the $\mathrm{VC}$ lesions were always between $2 \sim 5 \mathrm{~cm}$.

Histology: among 72 squamous cell carcinoma cases, high medium and low differentiated cases are respectively for $57(79.17 \%)$, 11(15.28\%), 4(5.56\%).
Lymph node involvement: 51 cases of inguinal lymph node resection, lymph node metastasis positive in 13 cases $(25.49 \%)$. With the decline in the degree of differentiation, lymph node metastasis gradually increased $(\chi 2=8.53 P=0.014<0.05)$.

Anemia occurred after surgery and anemia increase in 20 (25.97\%); 29 cases $(37.66 \%)$ of poor healing incision, 7 cases $(9.09 \%)$ of incision dehiscence, Lymphocele 6 (7.79\%) cases, all cases with conservative treatment. Thrombotic disease $3(3.9 \%)$ cases, turn to the relevant departments and improve later. Adhesion narrow urethra in one case, accounting for $1.30 \%$ of the surgery patients. Vaginal stenosis in 3 cases, accounting for $3.90 \%$ of the surgery patients.

Follow-up: Prior to 2009, the vast majority of patients lost the visit, and after the year of 2009, only 30 (35.29\%) cases can be followed-up. 8 of 30 cases $(26.67 \%)$ relapse, including 3 cases of 73 to 88 -year-old elderly patients who are in poor general condition and only did palliative surgery, had been recorded and died in the postoperative short-term. Six of eight cases of relapse patients are squamous cell carcinoma, 2 cases are malignant melanoma. Cases of High, medium and poorly differentiated SCC are respectively for 4,1,1. The shortest time of relapse after treatment is 2 months, the longest time is three years, the median time of recurrence is 15 months. 5 of 8 cases $(62.5 \%)$ of recurrence is vulvar local recurrence.

Table 1: Patients with treatment time and age distribution data (years).

\begin{tabular}{|c|c|c|c|c|c|c|}
\hline Groups & Mean age & No. of case & $\begin{array}{l}\text { Standard } \\
\text { deviation }\end{array}$ & Median age & F value & P values \\
\hline 2002-2004 & 63.3750 & 8 & 10.37769 & 62.5000 & \multirow{6}{*}{$\begin{array}{l}F=6.013 \\
P=0.016\end{array}$} & \\
\hline 2004-2006 & 62.6000 & 10 & 11.25660 & 65.0000 & & \\
\hline 2006-2008 & 59.4545 & 11 & 10.06344 & 56.0000 & & \\
\hline $2008-2010$ & 55.7059 & 17 & 10.39690 & 56.0000 & & \\
\hline 2010-2012 & 54.3333 & 39 & 14.85603 & 54.0000 & & \\
\hline Total & 57.0941 & 85 & 12.92526 & 58.0000 & & \\
\hline
\end{tabular}

Table 2: Patient's menopause status (\%).

\begin{tabular}{|c|c|c|c|c|c|c|c|c|c|c|c|c|}
\hline \multirow[b]{2}{*}{ Menopause } & \multicolumn{2}{|c|}{$02-04 \mathrm{yr}$} & \multicolumn{2}{|c|}{$04-06 y r$} & \multicolumn{2}{|c|}{ 06-08yr } & \multicolumn{2}{|c|}{$08-10 \mathrm{yr}$} & \multicolumn{2}{|c|}{$10-12 \mathrm{yr}$} & \multicolumn{2}{|c|}{ total } \\
\hline & $\begin{array}{l}\text { No. of } \\
\text { cases }\end{array}$ & $\%$ & No. & $\%$ & No. & $\%$ & No. & $\%$ & No. & $\%$ & No. & $\%$ \\
\hline Postmenopausal & 7 & 87.5 & 6 & 60.0 & 7 & 63.64 & 11 & 64.71 & 19 & 48.72 & 50 & 58.82 \\
\hline Premenopausal & 1 & 12.5 & 4 & 40.0 & 4 & 36.36 & 6 & 35.29 & 20 & 51.28 & 35 & 41.18 \\
\hline Total & 8 & 100.0 & 10 & 100.0 & 11 & 100.0 & 17 & 100.0 & 39 & 100.0 & 85 & 100.0 \\
\hline
\end{tabular}


Table 3: Patients with complications (\%).

\begin{tabular}{|lllllllll|}
\hline $\begin{array}{l}\text { Risk } \\
\text { factors }\end{array}$ & VNED & $\begin{array}{l}\text { Genitals } \\
\text { surgery }\end{array}$ & Malignancy & $\begin{array}{l}\text { Familial } \\
\text { malignant }\end{array}$ & $\begin{array}{l}\text { HPV } \\
\text { Infection * }\end{array}$ & Hypertension & Diabetes & obesity \\
\hline N & 25 & 23 & 19 & 2 & 4 & 10 & 13 & 33 \\
\hline$\%$ & 29.41 & 27.06 & 22.35 & 2.35 & 12.9 & 11.76 & 15.29 & 38.82 \\
\hline
\end{tabular}

Note: * The preoperative HPV testing by a total of $31(36.47 \%)$ patients;

Table 4: Vulvar cancer clinical manifestations.

\begin{tabular}{|lllllllllll|}
\hline \multicolumn{2}{|c}{ Genital tumor } & \multicolumn{2}{c}{ genital itching } & \multicolumn{2}{c|}{ genital ulceration } & \multicolumn{2}{c|}{ genital pain } & \multicolumn{2}{c|}{ other* } \\
\hline No. & $\%$ & No. & $\%$ & No. & $\%$ & No. & $\%$ & No. & $\%$ & 22 \\
\hline 60 & 70.59 & 48 & 56.47 & 34 & 40.0 & 30 & 35.29 & 22.88 \\
\hline
\end{tabular}

Note: *Others include vulvar bleeding, increased secretions, purulent exudates, white pigmentation

Table 5: History of present illness time distribution.

\begin{tabular}{|c|c|c|c|c|c|c|c|c|c|c|c|c|}
\hline \multirow[t]{2}{*}{$\begin{array}{l}\text { History } \\
\text { Time }\end{array}$} & \multicolumn{2}{|c|}{$\leq 2$ Month } & \multicolumn{2}{|c|}{2 Month to 1 year } & \multicolumn{2}{|c|}{1 to 3 years } & \multicolumn{2}{|c|}{4 to 6 years } & \multicolumn{2}{|c|}{7 to10 years } & \multicolumn{2}{|c|}{$>10$ years } \\
\hline & No. & $\%$ & No. & $\%$ & No. & $\%$ & No. & $\%$ & No. & $\%$ & No. & $\%$ \\
\hline $\begin{array}{l}\text { No. of } \\
\text { cases }\end{array}$ & 8 & 9.41 & 40 & 47.06 & 14 & 16.47 & 9 & 10.59 & 8 & 9.41 & 6 & 7.06 \\
\hline
\end{tabular}

Table 6: Location and size of the lesion.

\begin{tabular}{|c|c|c|c|c|c|}
\hline & \multicolumn{2}{|l|}{ Lesion site } & \multicolumn{3}{|c|}{ Lesion size } \\
\hline & Lateral type & In linear & $<2 \mathrm{~cm}$ & $2 \sim 5 \mathrm{~cm}$ & $\geqq 5 \mathrm{~cm}$ \\
\hline $\mathrm{N}$ & 62 & 23 & 16 & 59 & 10 \\
\hline$\%$ & 72.94 & 27.06 & 18.82 & 69.41 & 11.77 \\
\hline
\end{tabular}

Table 7: CT/MRI and pathologic comparison.

\begin{tabular}{|lllllllll|} 
& \multicolumn{1}{c}{ Tumor stage } & \multicolumn{3}{c|}{ Lesion location } & Lymph node \\
& 1A & 1B & 2 & 3 & in linear & lateral type & involvement \\
\hline CT/MR Results & 2 & 1 & 2 & 3 & 3 & 5 & 3 \\
\hline Pathological findings & 2 & 1 & 3 & 2 & 3 & 5 & 2 \\
\hline
\end{tabular}

Table 8: Clinical stage of vulvar excision.

\begin{tabular}{|lllll|}
\hline Surgical & I stage & II stage & III stage & Total \\
\hline Local excision of the genital lesions & 5 & 10 & 2 & 17 \\
\hline Some genital radical mastectomy & 2 & 3 & 3 & 8 \\
\hline Extensive vulvectomy & 0 & 1 & 0 & 1 \\
\hline $\begin{array}{l}\text { Partial vulvectomy + bilateral inguinal } \\
\text { lymphadenectomy }\end{array}$ & 16 & 13 & 2 & 31 \\
\hline $\begin{array}{l}\text { Extensive vulvectomy + bilateral inguinal } \\
\text { lymphadenectomy }\end{array}$ & 6 & 10 & 4 & 20 \\
\hline Total & 29 & 37 & 11 & 77 \\
\hline
\end{tabular}


Table 9: Vulvar extensions of surgical resection and recovery $(\%)$.

\begin{tabular}{|lllll|}
\hline Surgical & $\begin{array}{l}\text { No. of } \\
\text { cases }\end{array}$ & Infection & $\begin{array}{l}\text { Wound } \\
\text { dehiscence }\end{array}$ & $\begin{array}{l}\text { Average length } \\
\text { of stay (days) }\end{array}$ \\
\hline I & 17 & $1(5.88)$ & $0(0)$ & 12.18 \\
\hline II & 39 & $14(35.90)$ & $4(10.26)$ & 19.97 \\
\hline III & 21 & $14(66.67)$ & $3(14.29)$ & 41.48 \\
\hline Total & 77 & $29(37.66)$ & $7(9.09)$ & 24.12 \\
\hline$X^{2} /$ F Value & & 14.889 & 2.450 & 29.308 \\
\hline P Value & & 0.01 & 0.294 & 0.000 \\
\hline
\end{tabular}

Note: I simply lesion resection; II, part of vulvar radical with or without lymph node dissection; III, extensive vulvectomy with or without lymph node dissection.

Table 10: Inguinal lymph node dissection and wound recovery $(\%)$.

\begin{tabular}{|lllll|}
\hline Surgical & $\begin{array}{l}\text { The number } \\
\text { of cases }\end{array}$ & $\begin{array}{l}\text { infection/delayed } \\
\text { healing }\end{array}$ & $\begin{array}{l}\text { Wound } \\
\text { dehiscence }\end{array}$ & $\begin{array}{l}\text { Average length } \\
\text { of stay (days) }\end{array}$ \\
\hline I & 8 & $2(25.0)$ & $1(12.5)$ & 15.13 \\
\hline II & 31 & $12(38.71)$ & $3(9.68)$ & 21.23 \\
\hline$X^{2} /$ t Value & & $0.094^{\mathrm{a}}$ & $0.000^{\mathrm{a}}$ & 3.727 \\
\hline P Value & & 0.759 & 1.000 & 0.001 \\
\hline
\end{tabular}

Note: I, part of the vulvar radical mastectomy; II, part of vulvar radical + bilateral lymphadenectomy; a continuous correction of the chi-square value, uncorrected $\chi 2$ were $0.519,0.055, \mathrm{P}$ values were $0.417,0.815$

Table 11: Histopathological results (\%).

\begin{tabular}{|c|c|c|c|c|c|c|c|}
\hline & & $\begin{array}{l}\text { Squamous cell } \\
\text { carcinoma }\end{array}$ & $\begin{array}{l}\text { Basal cell } \\
\text { carcinoma }\end{array}$ & $\begin{array}{l}\text { Malignant } \\
\text { melanoma }\end{array}$ & $\begin{array}{l}\text { Outside } \\
\text { the breast }\end{array}$ & $\begin{array}{l}\text { Paget's } \\
\text { disease }\end{array}$ & Total \\
\hline \multirow{4}{*}{ 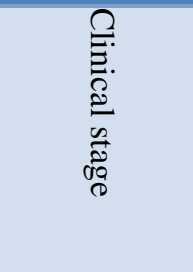 } & I & 23 & 4 & 1 & 1 & 1 & 30 \\
\hline & II & 37 & & 2 & 2 & & 41 \\
\hline & III & 11 & & 2 & & & 13 \\
\hline & IV & 1 & & & & & 1 \\
\hline \multirow{3}{*}{ 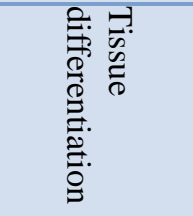 } & High & $57 \quad(79.17)$ & & & & & \\
\hline & In & $11(15.28)$ & & & & & \\
\hline & Low & $4(5.56)$ & & & & & \\
\hline \multirow{2}{*}{$\begin{array}{l}\text { Lymph node } \\
\text { Status } *\end{array}$} & positive & 11 & & 2 & & & 13 \\
\hline & Negative & 33 & & 3 & 1 & 1 & 38 \\
\hline
\end{tabular}

* Lymphadenectomy in 51 cases, 10 patients with pathologically confirmed ipsilateral lymph node metastasis, the pathologically confirmed three cases in linear transferred to bilateral lymph node, lymph node negative patients with lymphatic vascular invasion. 
Table 12: Histological grade and lymph node status.

\begin{tabular}{|lllll|}
\hline & & \multicolumn{2}{c}{ Lymph node status } & Total \\
\cline { 3 - 5 } & & Positive & Negative & \\
\hline \multirow{2}{*}{ Histological grade } & Well-differentiated & 5 & 26 & 21 \\
\cline { 2 - 5 } & In differentiation & 4 & 6 & 10 \\
\cline { 2 - 5 } & Poorly differentiated & 2 & 1 & 3 \\
\hline Total & & 11 & 33 & 44 \\
\hline
\end{tabular}

Table 13: Analysis of the vulvar cancer recurrence.

\begin{tabular}{|c|c|c|c|c|c|c|c|c|c|c|c|}
\hline \multirow[b]{2}{*}{ Surgical } & \multicolumn{3}{|c|}{ Clinical stage } & \multicolumn{3}{|c|}{$\begin{array}{l}\text { Organizational } \\
\text { differentiation }\end{array}$} & \multicolumn{3}{|c|}{ Surgical approach } & \multicolumn{2}{|l|}{ Recurrence site } \\
\hline & I & II & III & High & In & Low & I & II & III & $\begin{array}{l}\text { Simply vulvar } \\
\text { recurrence }\end{array}$ & $\begin{array}{l}\text { Lymph node } \\
\text { metastasis and } \\
\text { recurrence }\end{array}$ \\
\hline $\begin{array}{l}\text { Recurrent } \\
\text { cases }\end{array}$ & 0 & 3 & 4 & 3 & 1 & 1 & 2 & 2 & 3 & 5 & 2 \\
\hline$\%$ & 0 & 42.9 & 57.1 & 60 & 20 & 20 & 38.6 & 28.6 & 42.9 & 71.4 & 28.6 \\
\hline
\end{tabular}

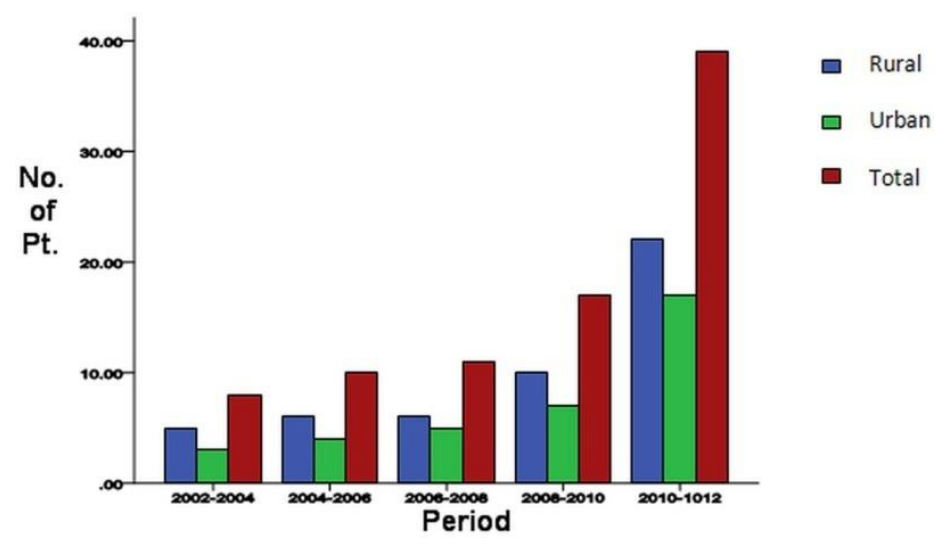

Figure 1: Vulvar cancer cases during the period (urban and rural case ratio).

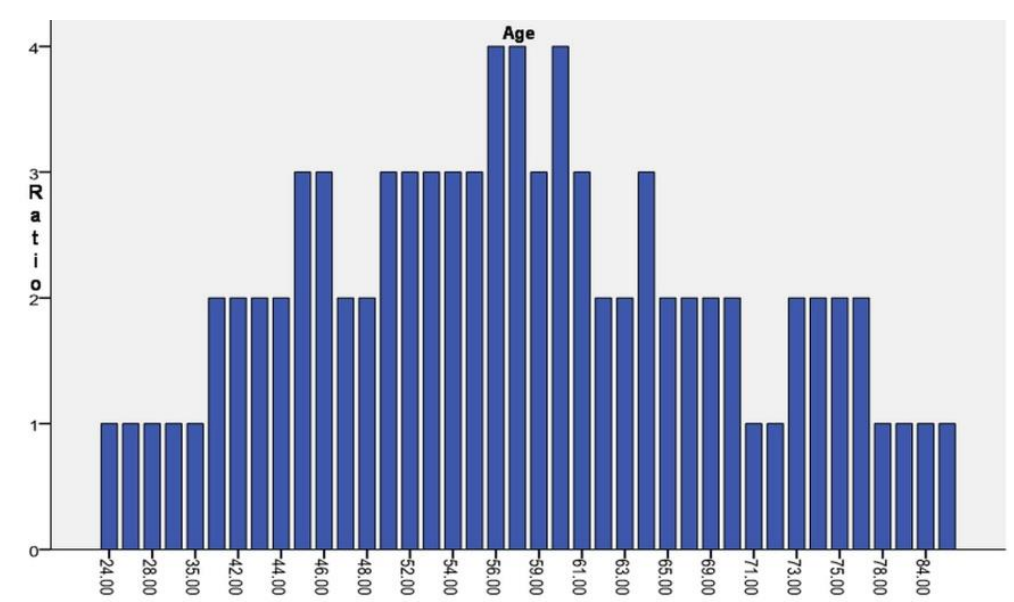

Figure 2: Age distribution of vulvar cancer patients. 


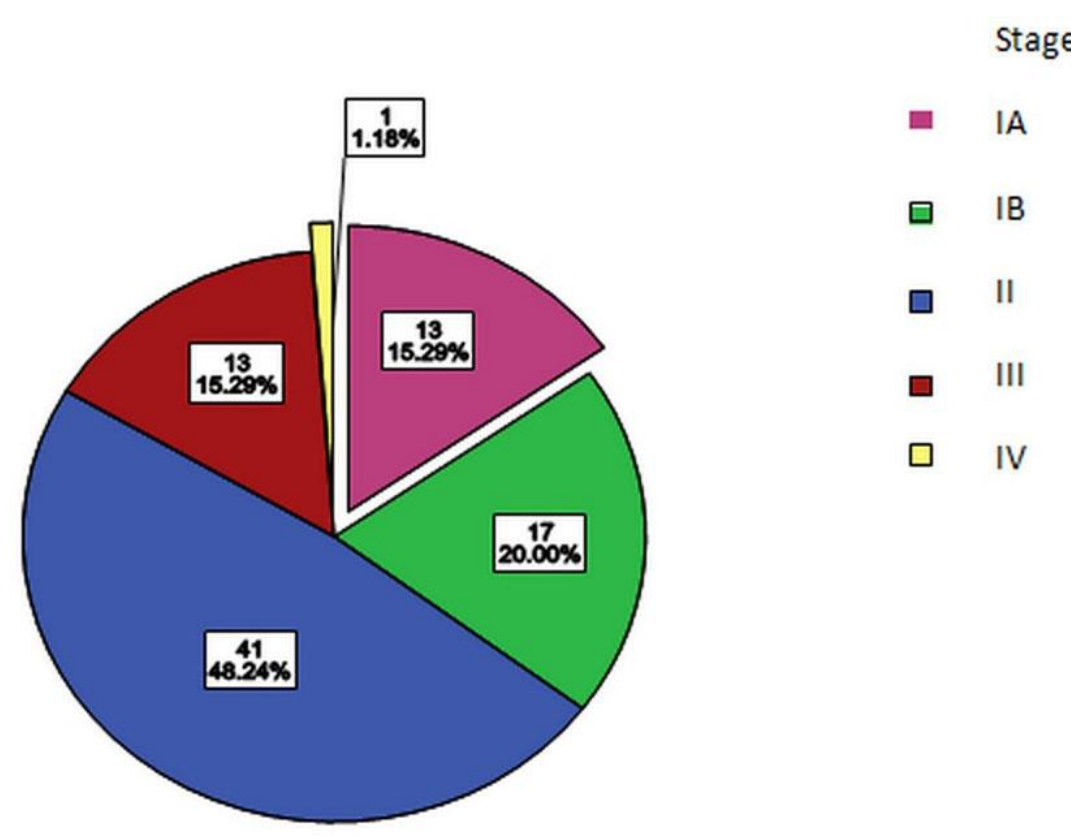

Figure 3: Stage distribution of carcinoma of the vulva.

\section{DISCUSSION}

Vulvar cancer is one of malignant tumor of the female genital tract. The incidence rate is about 2 to 3 cases / $100,000 .{ }^{1}$ Due to HPV infection and obesity its ratio increased rapidly. In future the rate of $\mathrm{VC}$ will continue to rise. The data from the Second Hospital of Jilin University, Changchun, China from 1991 to 2010, cases of VC analysis showed same. VC mainly occurred in rural patient but since 1991, the incidence in urban women has also been raised. However the incidence is still higher in rural patient $(56.41 \%)$ than urban $(43.59 \%)$. According to previous reports in recent years, there have been significant rising trend of VC in younger age. ${ }^{5}$ In this study, the age distribution ranges from 24 to 88 -yearold, with average age $57.09 \pm 12.93$ years old, and with a peak age of 56 to 61-year-old. The mean age of onset at different period from 2002-2012 was $63.38 \pm 10.38$ years which dropped in 2010-2012 to $54.33 \pm 14.86$ years. After the statistical analysis, the age of onset of $\mathrm{VC}$ declines year by year, this shows consistent ratio with the previously reported literatures. 50 cases with $\mathrm{VC}$ were postmenopausal accounting for $58.82 \%$; it's also consistent with the literature. ${ }^{6}$ Studies have shown that there is some correlation between white lesion of vulva and progesterone levels. Higher the progesterone levels, higher the risk of white lesions of the vulva while the white vulva is one of the common causes of VC. ${ }^{7}$ Studies have shown that HPV infection and VC are closely related to the occurrence of the HPV virus detection rate (40.4\%), i.e. common type of HPV 16,33, and $18 .^{8}$ Lichen sclerosis has $4 \%$ to $6 \%$ of the possibility of the development of VC. ${ }^{9}$ In this study obesity, VNED, HPV infection, Hypertension, Diabetes mellitus, and history of genital surgery accounted for 33 cases $(38.82 \%), 25$ cases
(29.41\%), 4 cases (12.9\%), 10 cases (11.16\%), 13 cases $(15.29 \%)$, and 23 cases $(27.06 \%)$ respectively. By statistical analysis VC occurrence, VNED and HPV infection had no significant correlation with sample size, considering the possibility of fewer and lower rates of HPV screening. High-risk group's patient is recommended to have regular physical examinations to improve the early diagnosis and early treatment. Longterm genital itching is the earliest common symptom in most patients. Other symptoms include genital or genital ulcer, genital or vulvar mass, genital bleeding, dysuria, and pain. On physical examination visible genital lumps or ulcers, may be associated with the surrounding skin hypopigmentation, hyperpigmentation plaques, macules or papules. Data showed that, Genital lesions were located to lateral side i.e. more consistent with the literature. Most of the patient in this study had lesion size between $2 \mathrm{~cm}-5 \mathrm{~cm}$. In recent years, some scholars have pointed out that the vulvar cytology initial screening of malignant lesions of the vulva is reducing unnecessary biopsy. In this study, 85 patients with VC, 78 patients. underwent biopsy; the biopsy rate was $91.76 \%$. The biopsy coincidence rate of $93.58 \%$ (73/78), 5 cases of biopsy and postoperative pathological discrepancies (including 1 case of the vulva melanin cell nevus, malignant melanoma, biopsy diagnosis of localized squamous epithelium was light - moderate dysplasia, verrucous squamous cell carcinoma, biopsies extramammary Paget's disease, well-differentiated squamous cell carcinoma, 1st case diagnosed as genital chronic inflammation, the 2nd of well-differentiated squamous cell carcinoma); routine colposcopy shows the vulval local vascular in a mosaic, intraoperative rapid pathological diagnosis - poorly differentiated vulvar squamous cell carcinoma. Literature prompted the high 
specificity of CT examination in the judgment of VC lymph node metastasis therefore has an important applications in the preoperative staging. ${ }^{10}$ The presence of CT examination overestimates or underestimates the clinical stage possibility. CT should determine the presence or absence of lymph node metastasis, to be based on the number of lymph nodes and the size of the lymph node. ${ }^{11}$ Information found metastasis more overlap between lymph node size, but the difference was statistically significant $(\mathrm{P}=0$. 019). Lymph node enlargement shows the highest incidence of lymph node metastasis. Prompted less, no lymph nodes involved preoperative diagnosis of 85 cases of vulvar cancer patients in this study CT in 6 cases, MR 2 cases which is very small sample size. Minimally invasive surgery is the hot spot trends nowadays. On Traditional open laparotomy; it is difficult to dissect inguinal lymph node. It may damage to large internal organs, incision healing difficulties and others postoperative complication. While of laparoscopic inguinal lymph node dissection, minor trauma may occur, hospital stay is short length, and faster wound healing are the best prospects. Postoperative incision infection of valvular resection had significant influence on hospitalization time $(\chi 2=14.889, \mathrm{P}=0.01$ $<0.05 ; \mathrm{F}=29.308, \mathrm{P}=0.000<0.01)$. Therefore, treatment of vulvar lesion should be according to the stage. At the early stage of VC it may be appropriate to reduce the scope of operation, $2 \mathrm{~cm}-3 \mathrm{~cm}$ above the cutting edge, and operation of properly preserved subcutaneous tissue thickness, can increase blood circulation, and relieve tension incision healing to promote the incision. Routine preservation of the saphenous vein during inguinal lymph node resection for VC significantly can shorten the operative time, reduce the lymphatic vessels and peripheral nerve injury, and incidence of hematoma. ${ }^{12} \mathrm{VC}$ patient using the implementation of the inguinal lymph node dissection do not make patients benefit, but can increase the incisional infection, dehiscence and chronic lymphatic swelling and other postoperative complications. Hampl on routine SLN biopsy in 127 patients with T1-T3, VC in 125 patients, 36 of 39 cases dissected lymph node-positive patients with positive SLN biopsy, a sensitivity of $92.3 \% .^{13} 3$ false negative SLN patients $(7.7 \%)$ are located in the midline of the primary tumor. Ultra installments negative predictive value of sentinel lymph node biopsy (NPV) from $97 \%$ to $100 \%$ Studies have shown that less than $4 \mathrm{~cm}, \mathrm{~T} 1$ or T2, infiltration depth of less than $1 \mathrm{~mm}$ of vulvar squamous cell carcinoma were treated with sentinel lymph node biopsy has better security and accuracy. ${ }^{14,15}$ Information has not yet been adopted sentinel lymph node biopsy technique therefore should improve preoperative lymph node biopsy technique. Early VC sentinel lymph node biopsy shows: 1) pathology screening micrometastasis, there are still some difficulties need to develop such as tissue microarray technology, has higher sensitivity. Combination of molecular biology techniques such as RT-PCR detection of sentinel lymph node does not yet have clinical utility. ${ }^{16}$ De Hutu suggests that the use of the methylene blue assay SLN sensitivity of only $60 \%$, hematoxylin-eosin staining sensitivity of $80 \%$. Combined with immunohistochemical techniques for tumor antigens can be detected by the presence of micrometastasis, to achieve tumor "super stage". ${ }^{17}$ The incidence of genital extramammary Paget's disease in this study is consistent with the literature. ${ }^{18}$ The disease lesions confined to the epidermis had better prognosis. ${ }^{19}$ In research it is still controversial about the margin on the pathological type of operation. Black et $\mathrm{al}^{20}$ considered the pathological positive margins leading to post-operative recurrence rate were significantly higher (70\% and $38 \%)$. In this study patients surgically treated was pathologically confirmed as negative margins. In VC malignant degree of differentiation pathological type differs prognostic factors and treatment are also different. Therefore, tumor biopsy before treatment is still an important method to guide the diagnosis and follow up treatment. The exudation from the incisional operated wound, there are chances of skin infection, cellulitis and formation of lymphatic cyst. Therefore to prevent the oozing of blood it is essential to have the proper dressing and drainage of the wound to prevent wound infection and promote wound healing. Often with the 24 hours $1-1.5 \mathrm{~kg}$ weight compression is given to the patient with indwelling drainage tube, should maintain the negative pressure suction for 4-6 days. The negative pressure can be maintained at about $0.98 \mathrm{kPa}$. Drainage bag should be changed daily. The main prediction factors for locally recurrent valvular cancer are 1) operating margin of tumor is near or close, 2) the depth of tumor invasion $>5 \mathrm{~mm}, 3$ ) lymphatic vessel invasion and tumor infiltration growth pattern. The main predictors of groin, pelvis and distant recurrence factors are the numbers of lymph node metastasis and tumor differentiation or histopathological grade. ${ }^{21} \mathrm{We}$ should strengthen the patient awareness regarding the disease and its outcome. Establish the appropriate follow up file tracing control on the therapeutic effect of disease so as to improve the level of diagnosis and treatment. The follow up rate is low, so it is difficult to analyze the related factors of recurrence and calculate the survival rate in years. With these entire data prognosis cannot be predicted.

\section{CONCLUSION}

$\mathrm{VC}$ number increased year by year, the onset ages of the VC had a younger trend; VC patients were mainly in rural. Malignant tumor history and obesity have the positive correlation with VC onset. For high-risk groups should be positive for the disease, the Suggestions to do regular physical examining. For longer-term genital itching, genital tumor, genital ulcers, and other symptoms, should be alert to the possibility of vulvar cancer, in order to reduce the misdiagnosis cases. Preoperative diagnosis should be colposcopy, biopsy, combined with the advantages of each, in order to improve the accuracy of earlier diagnosis, should strengthen the CT and MRI of preoperative diagnosis in the application. Vulvar resect scope may have an effect on the healing of the incision. Vulvar postoperative major 
complications is wound infection, no special complications; Follow-up rate is low, with small recurrence cases, it is difficult to analyze the factors associated with recurrence; No established disease diagnosis and treatment to cross over files, difficult to statistical 5-year survival rate.

Authors' contribution: Prof. Zheng Guiying was the coordinator of the study. Raghvendra Thakur carried out most of the experimental design, data interpretation and writing manuscript. All co-authors contributed for conception, data collection and helped in manuscript preparation.

\section{ACKNOWLEDGMENTS}

The authors would like to thank Bhojraj Sharma and Nijamudin for help with manuscript preparation.

\section{Funding: None}

Conflict of interest: None declared

Ethical approval: Not required

\section{REFERENCES}

1. Woelber L, Kock L, Gieseking F, et al Clinical management of primary vulvar cancer. Eur J Cancer 2011;47:2315-21.

2. Gillison ML, Chaturvedi AK, Lowy DR. HPV prophylactic vaccines and the potential prevention of noncervical cancers in both men andwomen [J]. Cancer, 2008, 113(10 Suppl): 3036-3046.

3. Pecorelli S. Revised FIGO staging for carcinoma of the vulva,cervix, and endometrium [J]. Int $\mathrm{J}$ Gynecol Obstet, 2009, 105(2): 103-104.

4. Scott D,Richard,Krivak,et al.Recurrent metastatic vulvar carcinoma treated with cisplatin plus cetuximab. Int J Gynecol cancer,2008 ; 18:11321135.

5. Hampl M, Sarajuuri H, Wentzensen N, et al. Effect of human papillomavirus vaccines on vulvar, vaginal, and anal intraepithelial lesions and vulvar cancer [J]. Obstet Gynecol, 2006, 108(6): 13611368.

6. Ji Feng, Shen Keng. Obstetrics and Gynecology [M]. 2nd edition, Beijing: People's Health Publishing House, 2010, 321-324.

7. Hyosung Geng, Li Yun, Cheng Likun. The diagnosis and treatment of vulvar cancer [J] Journal of Practical Oncology, 1992, 2: 67-69.

8. Jennifer Smith,Danielle Backes,Brooke Hoots. Human Papillomavirus Type-Distribution in Vulvar and Vaginal Cancers and Their Associated Precursors [J]. Obstet Gynecol 2009,;113(4):917-24.
9. Funaro D. Lichen sclerosus: a review and practical approach [J].Dermatol Ther, 2004, 17(1): 28-37.

10. Zhujun Rong Lei Xiaomin, Xu Hua Hong clinical value of CT diagnosis of vulvar cancer [J]. Journal of Practical Obstetrics and Gynecology, 2011, 27 (9) :707-709.

11. McMahon CJ,Rofsky NM,Pedrosa I.Lymphatic metastases from pelvic tumors: anatomic classification, characterization, and staging $[\mathrm{J}]$ - Radiology, 2010, 254(1): 31-46.

12. Dardarian TS, Gray HJ, Morgan MA, et al. Saphenous vein sparing during inguinal lymphadenectomy to reduce morbidity in patients with vulvar carcinoma [J]. Gynecol Oncol, 2006 , 101 (1): 140-142.

13. Hampl M, Hantschmann P, Michels W, et al. Validation of the accuracy of the sentinel lymph node procedure in patients with vulvar cancer: results of a multicenter study in Germany [J]. Gynecol Oncol, 2008, 111(2): 282-288.

14. Levenback CF. How Safe Is Sentinel Lymph Node Biopsy in Patients with Vulvar Cancer [J]? J Clin Oncol, 2008, 26(6): 828-829.

15. Vidal-Sicart S, Puig-Tintore LM, Lejarcegui JA, et al. Validation and application of the sentinel lymph node concept in malignant vulvar tumours[J]. Eur J Nucl Med Mol Imaging, 2007, 34(3): 384-391.

16. Rutgers EJT. Sentinel Node Biopsy: Interpretation and Management of Patients With Immunohistochemistry-Positive Sentinel Nodes and Those With Micrometastases[J]. J Clin Oncol, 2008, 26(5): 698-702.

17. Lupi G,Raspagliesi F,Zucali R,et,al.Combined preoperative chemoradiotherapy followed by radical surgery in locally advanced vulvar carcinoma Cancer, 1996,77:1472.

18. Tebes S, Cardosi R, Hoffman M. Paget ' $s$ disease of the vulva $[\mathrm{J}]$. Am J Obstet Gynecol, 2002, 187 (4): 281-284.

19. Jones ISC, Crandon A, Sanday K, et al. Paget ' $\mathrm{s}$ disease of the vulva: diagnosis and follow-up key to management; a retrospective study of 50 cases from Queensland [J].Gynecol Oncol, 2011, $122(2): 42-44$.

20. Black D, Tornos C, Soslow R, et al. The outcomes of patients with positive margins after excision for intraepithelial Paget ' $\mathrm{s}$ disease of the vulva [J].Gynecol Oncol, 2007, 104 (3): 547-550.

21. Maggino T, Landoni F, Sartori E, et al. Patterns of recurrence in patients with squamous cell carcinoma of the vulva: a multicenter CTF study. Cancer 2000;89:116-22.

DOI: $10.5455 / 2320-1770 . i j r \operatorname{cog} 20130903$

Cite this article as: Thakur R, Xuehua Z, Mengli Z, Yanjun W, Yuan T, Guiying Z. Clinical analysis of vulvar cancer. Int J Reprod Contracept Obstet Gynecol 2013;2:268-76. 